"This book adds to our understanding of the role of informal learning as a critical contributor to the future of schooling in a wired global context. The authors show how informal learning deepens and broadens what is learned formally and also contributes to student growth and development while helping solve local and global challenges."

-Karen E. Watkins, Professor and Associate Department Head, Department of Lifelong Education, Administration, and Policy (Adult Education, Learning and Organization), The University of Georgia, USA 
Serafina Pastore - University of Bari - 13/05/2020 


\section{Schools and Informal Learning in a Knowledge-Based World}

This book has two purposes: To open up the debate on the role of informal education in schooling systems and to suggest the kind of school organizational environment that can best facilitate the recognition of informal learning. Successive chapters explore what is often seen as a duality between informal and formal learning. This duality is particularly so because education systems expend so much time and effort in certifying formal knowledge often expressed in school subjects reflecting academic disciplines. Recognizing the contribution informal learning can make to young people's understanding and development does not negate the importance of valued social knowledge: That complements it. Students come to school with knowledge learnt from their families, peers, the community and both traditional and social media. They should not have to "unlearn" this in order to enter the world of formal learning. Rather, students' different learning "worlds" should be integrated so that each informs the other. In a knowledge-based society, all learning needs to be valued.

Some contributors to this book reflect on how new educational systems could be created in a move away from top-down authoritarian and bureaucratic management. Such open systems are seen to be more welcoming in acknowledging the importance of informal learning. Others provide practical examples of how informal learning is currently recognized. Some attention is also paid to the evaluation of informal learning. A key objective of the work presented here is to stimulate debate about the role of informal learning in knowledge-based societies and to stimulate thinking about the kind of reforms needed to create more open and more democratic school learning environments.

Javier Calvo de Mora is a Professor of School Organisation at the University of Granada, Spain. His main research interest is in policy, institutional collaboration and leadership studies. He is currently coordinator of the European Network on Research on Citizenship Education.

Kerry J. Kennedy is Professor Emeritus, Advisor (Academic Development) and Senior Research Fellow in the Centre for Governance and Citizenship at The Education University of Hong Kong. He is also a Distinguished Visiting Professor at the University of Johannesburg. 


\section{Asia-Europe Education Dialogue \\ Series Editor: Kerry J. Kennedy}

This Routledge book series provides a forum for dialogue on key educational issues and challenges faced by Asian and European societies. Its distinctiveness is its broad focus on Education in Asia and Europe. In essence, it will address major issues in education reform, student learning, leadership, curriculum, higher education, multicultural education and other major educational issues affecting Asia and Europe.

Published books:

\section{Class Size}

Eastern and Western Perspectives

Edited by Peter Blatchford, Kam Wing Chan, Maurice Galton, Kwok-Chan Lai and John Chi-Kin Lee

\section{Higher Education in the Asian Century}

The European Legacy and the Future of Transnational Education in the ASEAN Region

Edited by Christopher Hill and Rozilini M. Fernandez-Chung

Theorizing Teaching and Learning in Asia and Europe

A Conversation between Chinese Curriculum and European Didactics Edited by John Chi-Kin Lee and Kerry J. Kennedy

Young People and Active Citizenship in Post-Soviet Times

A Challenge for Citizenship Education

Edited by Beata Krzywosz-Rynkiewicz, Anna M. Zalewska and Kerry J. Kennedy

Schools and Informal Learning in a Knowledge-Based World Edited by Javier Calvo de Mora and Kerry J. Kennedy

URL: https://www.routledge.com/Asia-Europe-Education-Dialogue/bookseries/AEED 


\section{Schools and Informal Learning in a Knowledge- Based World}

Edited by Javier Calvo de Mora and Kerry J. Kennedy 
First published 2020

by Routledge

2 Park Square, Milton Park, Abingdon, Oxon OX14 4RN

and by Routledge

52 Vanderbilt Avenue, New York, NY 10017

Routledge is an imprint of the Taylor \& Francis Group, an informa business

(C) 2020 selection and editorial matter, Javier Calvo de Mora and Kerry J. Kennedy; individual chapters, the contributors

The right of Javier Calvo de Mora and Kerry J. Kennedy to be identified as the authors of the editorial material, and of the authors for their individual chapters, has been asserted in accordance with sections 77 and 78 of the Copyright, Designs and Patents Act 1988.

All rights reserved. No part of this book may be reprinted or reproduced or utilised in any form or by any electronic, mechanical, or other means, now known or hereafter invented, including photocopying and recording, or in any information storage or retrieval system, without permission in writing from the publishers.

Trademark notice: Product or corporate names may be trademarks or registered trademarks, and are used only for identification and explanation without intent to infringe.

British Library Cataloguing in Publication Data

A catalogue record for this book is available from the British Library

Library of Congress Cataloging in Publication Data

A catalog record for this book has been requested

ISBN: 978-0-367-07756-3 (hbk)

ISBN: 978-0-429-02261-6 (ebk)

Typeset in Galliard

by Cenveo ${ }^{\circledR}$ Publisher Services 
Javier would like to dedicate this book to his sons, Willian and Eduard, and his grandson, Hiryu; and Kerry would like to dedicate it to his grandchildren, Zoe, Jamie, Oliver, Henry, Annabele, Rose, Fletcher and Sam 
Serafina Pastore - University of Bari - 13/05/2020 


\section{Contents}

List of figures $\quad \mathrm{xi}$

List of tables $\quad$ xii

Series editor's note xiii

List of contributors $\quad \mathrm{XV}$

1 Towards a new educational contract JAVIER CALVO DE MORA

\section{PART I}

Schools and informal learning: Shaping the future

2 What we really learn in school?

ROGER C. SCHANK

3 Exploring the foundations of informal learning

4 Inventing a public education system for the 21 st century JOHN H. FALK

5 The relationship between formal and informal learning DANIEL A. TILLMAN, SONG A. AN, AND WILLIAM H. ROBERTSON

\section{PART II}

6 Asian students' informal civic learning: Can it enhance civic knowledge and values? 
7 The Shanghai model for global geography education

OSVALDO MUÑIZ SOLARI AND LIANFEI JIANG

8 Academic family and educational Compadrazgo:

Implementing cultural values to create educational relationships for informal learning and persistence for Latinx undergraduates

ALBERTA M. GLORIA, JEANETT CASTELLANOS, MARY DUEÑAS, AND VERONICA FRANCO

9 Formal-informal, exclusion-inclusion: An empirical investigation of Swedish music education

\section{PART III}

Informal learning as lifelong learning and its evaluation

10 Governance of informal learning as a pathway for the development of young adults' agency for sustainability

VALĒRIJS MAKEREVIČS AND DZINTRA ILIŠKO

11 Integrating formal and informal learning to develop self-management skills: Challenges and opportunities for higher education in the university-to-work transition AMELIA MANUTI

12 Informal learning assessment

JAVIER CALVO DE MORA

13 Is an "avant-garde" assessment? The certification of competencies in the Italian higher education system SERAFINA PASTORE

14 Conclusion: Open schools and shared responsibilities: Integrating informal and formal learning in 21st-century schools 


\title{
13 Is an "avant-garde" assessment? The certification of competencies in the Italian higher education system
}

\author{
Serafina Pastore
}

\section{A note to begin}

Over the last 20 years, within the adult education field, the concept of learning has been consistently reviewed for its epistemological, social and policy implications (Bron \& Schemmann, 2003; Feutrie, 2008; Jarvis, 2011).

Lifelong learning has been considered as a strategic lever for economic growth and social stability (Coffield, 2000; Evans, 2000). In this way, lifelong learning has been legitimated because it allows individuals to

- overcome the idea that education and learning are related only to formal contexts (e.g. school and higher education);

- respond to the social need of acquiring knowledge and competencies that are not necessarily related to the workplace but can be functional to the daily life;

- deal with economic, social and technological transformations.

In relation to European policies, the principles of dignity, autonomy, active citizenship, personal self-attainment, social inclusion and employability have influenced the concept of learning (Rogers, 2014). From this perspective, informal learning-defined as a kind of learning that is not didactic, embedded in meaningful activities, building on the learners' initiatives, interests or opportunities-has become part of the debate. This is due to the need to develop approaches, models, strategies and instruments aimed at assessment of this kind of learning.

The present chapter focuses on the assessment of informal learning, and more specifically on the certification of competencies within the Italian higher education system. To this end, in the first section, contexts and trends around informal learning, and the recognition, validation and certification of competencies are introduced. While initial attempts at validation and certification of informal learning have experimented with new approaches, models and practices of assessment, more recently several pitfalls (e.g. lack of evidence for validity) seem to undermine the power of this "avant-garde" assessment. Moving from the several meanings, and practical implications, of recognition of informal learning, the 
purpose of this section is to discuss validity in the assessment of informal learning. In the next section, the chapter tries to connect the international debate over higher education governance with models and practices of certification of competencies realized in the Italian context. The final section considers limitations and identifies areas requiring further research.

\section{Recognition, validation and certification: One rationale, many practices}

The processes of recognition, validation and certification of informal learning require us to identify and make visible the knowledge, competencies and experience acquired by a learner in different contexts. Within the lifelong and life-wide learning perspective, it is important to identify these processes and to value the learning that takes place anywhere and anytime in the life of the individual.

In European documents, recognition and validation of informal learning are considered, although from a more economic perspective, as a key aspect for the effective development of lifelong learning (Collardin \& Bjørnåvold, 2005). The recognition and validation of informal learning can help individual learners to better understand the knowledge society and to better pursue their personal learning needs (CEDEFOP, 2000). All the key documents in the European area mention the equivalence of learning acquired by a learner as a fundamental principle of lifelong learning.

"Recognition", from a UNESCO perspective, is a practice that "renders visible and gives value to the hidden and unrecognized competencies that individuals have obtained in various contexts through various means in different phases of their life. Valuing and recognizing these learning outcomes may significantly improve individual's self-esteem and well-being, motivate them to further learning and strengthen their labour-market opportunities. [Recognition, validation and accreditation practices] may help to integrate broader sections of the population into an open and flexible education and training system and to build inclusive societies" (Rogers, 2014; p. 3).

Giving official status to competencies, or learning outcomes, is only one of the possible meanings of "recognition." There are other aspects to be considered such as acknowledgement of the value that skills and competencies have in terms of employability or academy transferability; there is the acceptance of this assessment process by different stakeholders (education, training, labour market); there are, lastly, the social value and the embedded nature of learning within a specific context (Michelson, 2006; Singh, 2015).

What exactly do we mean by "validation" and "certification"? Validation, as a form of recognition of personal and professional competencies, in line with CEDEFOP (2009), consists of external attestation of learning outcomes achieved by a learner in formal, non-formal and informal contexts. These learning outcomes are judged against defined criteria and standards: In this way, they can be used for certification and recognition of credits gaining admission and advance standing or credits in higher education (Andersson \& Guo, 2009; Jarvis, 2011). 
Certification is a process to formally validate knowledge, know-how and/or competencies acquired by an individual, following a standard assessment procedure (Jackson, 2011). In this process the European Qualification Framework (EQF) has an important role. This is a common framework through which to view description, comparison and contrast of qualifications, certificates and diplomas in different countries in order to facilitate work mobility.

The attention given to validation, as a means for equity and inclusion in education, as a social and professional field (Jackson, 2011), has progressively influenced not only educational research but also policy and decision-making. Different European countries, agreeing with the importance of validation and certification of informal learning, have expressed the need to make learning "beyond the classroom" visible and to value it in a more responsive and effective way. With the European Guidelines for Validating Non Formal and Informal Learning, the CEDEFOP (2009) provided a scheme, a model, based on three main phases:

1 Identification: This phase identifies competencies considering previous learning experiences and lists which competencies can be submitted for validation. This phase includes meetings to re-construct, with reference to educational and professional standards, the learner's experience.

2 Valuation: Competencies identified in this phase are assessed in terms of mastery and levels of conformity to the standards.

3 Validation: This is the end phase of the process with a decision-making result. Generally, there is a commission with experts and independent stakeholders.

Different approaches have been developed over the years (e.g. first in France and United Kingdom and then in Norway, Sweden, Denmark) with a focus on different contexts (e.g. workplace, vocational education and training, higher education) for different targets (e.g. migrants, women, students) and different aims. In 2012, the European Council issued the Recommendations for the Validation of Non-Formal and Informal Learning, asking all member nations to define within 2018 "necessary arrangements for validation." However, given the upsurge of methodologies and strategies designed to recognize, validate and certificate competencies, a concern has been expressed (CEDEFOP, 2009) that "solutions are looking for problems" highlighting an overproduction of methods and devices in comparison to the real needs of certification.

Different studies (Andersson, Fejes, \& Sandberg, 2013; Andersson \& Harris, 2006; Bjørnåvold, 2000; Castle \& Attwood, 2001; Fenwick \& Parsons, 2000) confirm how complex and problematic recognition of informal learning appears to be. More than this, these studies demonstrate how informal learning, even within the consistent legislative framework, has not had sufficient recognition. Pitman (2009) shows the difficulties for implementation of validation especially when this process is related to social inclusion. Some studies highlight how the power of validation in terms of liberty, social justice and equity may 
be underestimated. The comparative analysis realized by the EU Commission in 2010 confirms how weak, across the EU countries, the processes of recognition and validation may be. A latent paradox becomes evident here: Some people may be made despondent by the process of validation and, as a negative consequence, social exclusion may grow. Furthermore, what is becoming clear is the difficulty of integrating validation and certification practices into formal education systems (Council of the European Commission, 2012). In their comparative study Slowey and Schuetze (2012) address what kind of factors may constrain or facilitate access to validation practices:

- The need to differentiate between the grade awarded, in horizontal (meaning the progress through the system) and vertical (meaning consistent grades when changing from one institution to another) terms, within an education system.

- The level of autonomy and flexibility that education institutions have over assessment arrangements.

- The accessibility to lifelong learning programmes.

- The organization of learning paths.

- The financial supports.

- The identification of concrete chances of continuous learning.

Alternatively, Werquin $(2010,2014)$ underlines the main critical issues in validation:

- The limited opportunities for individuals to access validation practices.

- The lack of coherence between different validation approaches.

- The lack of a unique definition of validation in terms of policy.

Although the European Union has defined a common framework, there are many differences, sometimes substantial, among the European countries. In order to take account of the complex validation landscape, in 2014, the CEDEFOP with the European Inventory on Validation of Non-Formal and Informal Learning gave a detailed snapshot of the state of the art. The Inventory underlines how the gap is relevant in the development of validation and certification systems: While great attention has been reserved to the effects of validation, few efforts have been made in theoretical (what validation is and what it can accomplish) and methodological terms (approaches and practices of validation).

The scenario is not coherent and cohesive. If on the one hand, there are consistent signs of progress in the definition of achievable aims, on the other hand, there are some unresolved assessment dilemmas (e.g. who does the validation? Which criteria have to be considered in this assessment process?) Considering the impact that the results of recognition, validation and certification have, especially as expanding practices in the higher education context, these assessment processes have to be regarded more carefully. In order to methodologically 
frame the complex landscape of validation, the next section considers a thorny problem: The validity criteria.

\section{Assessment dilemmas: To validate or not to validate?}

Approaches and models of validation of informal learning have their rationale in the recognition of experience as a fundamental criterion for learning: Validation focuses on knowledge, abilities and competencies acquired by an individual during and through experience. If recognition is the process by which an individual's prior learning experiences are assessed as being equivalent to specific formal learning outcomes (Pitman \& Vidovich, 2013), validation consists of a translation to a formal level of learning achievement. In this perspective, there is a relevant amount of research on recognition and validation of informal learning focused on the concepts of transfer and on equivalence of learning (Cooper \& Harris, 2013; Harris, 2000; Trowler, 1996).

Over the years the debate on recognition and validation developed and reinforced the idea of credentialed (higher education and vocational education training) and un-credentialed (work and life experience) learning. An unresolved knot, however, remains: Is it appropriate to assess informal learning using the same criteria used for the assessment of formal learning?

Beyond the obvious observation that informal learning has its own qualities, the validation process hides the rationale of mere transposition and arrangement of informal learning to the features and criteria of formal learning. Collardin and Bjørnåvold (2005) pointed out that "there is no indication that the challenge of validate of non-formally and informally acquired competencies has led to the development and introduction of genuinely new testing and assessment methods ... [the] object (of non-formal and informal learning) to be measured is different and more complex making the requirements to reliability and validity very harder to reach" (p. 117).

Methods used in validation started to overlap with traditional methods used for the assessment of learning in formal contexts and lead to an unclear distinction of assessment aims, strategies and practices.

Previous attempts to define the proprium (essential characteristic) of the validation process of informal learning have generally borrowed too heavily from approaches to the assessment of formal learning. They have also determined a varied corpus of strategies rooted in theoretical approaches (narrative/ biographical/diagnostic) which are different and sometimes conflicting.

Following the CEDEFOP Guidelines $(2000,2009)$ it is possible to distinguish several methods for the validation of informal learning:

- Debate

- Declarative methods

- Interview

- Observation

- Presentation

- Simulation and performance

- Test 
In spite of the confusing array of methods, techniques and practices, a common element remains: Gather evidence of learning in terms of what a learner knows, says, writes or is able to do in order to make visible non-formal and informal learning and get recognition from formal assessment systems. Interpretation is strictly related to the quality of inferences made about a learner's achievement, and this impacts on the validation results. In this vein, data and logic should be assembled into arguments - pro or contra-for the recognition, validation and certification of specific informal learning: All assessments require validity because without validity assessments have little or no intrinsic meaning (Newton, 2007; Nyström, 2004).

There have been considerable efforts to develop and improve structures, mechanisms and methods for recognition of all forms of learning, and to establish equivalency frameworks. However, there is a latent difficulty in comparing and contrasting different practices implemented in, across and beyond Europe due to the strong gradient of context sensitivity and the scant attention paid to validity: "As the role of assessment procedures is to provide decision-makers with correct and relevant information, it is of great importance to examine issues regarding the quality, utility and fairness in this type of assessment" (Stenlund, 2010, p. 783). Assessment and evaluation practices are not "valid or invalid" but rather the informal learning has more or less evidence to support or refute a specific interpretation (such as certifying or not a learner's competence).

\section{Validity: A missing criterion?}

In the educational assessment field the validity concept, over the years, has changed considerably. During the 1980s and 1990s validity has inspired a lively debate between a "traditional" vision and a "modern" perspective due to the increased use of assessment across scientific, social and educational settings (DeLuca, 2011; Kane, 2016). The validity is considered in terms of correspondence between detection, measurement, judgment and the assessment object. An instrument is valid when it reflects the intention of the researcher/evaluator. Traditionally, a test is valid "for anything with which it correlates" (Guilford, 1946, p. 429) or if "it measures what it purports to measure" (Shepard, 1993, p. 410). Recently DeLuca (2011) pointed out how, over the years, these synthetic definitions have become more and more complex to the point that it is possible to distinguish between the following kinds of validity:

- Content validity: Tests describe a performance in a specific field. This validity is about the correlation between the measure and what the instrument measures.

- Criterion validity (predictive): This validity is related to the accuracy of the test.

- Construct validity: This validity is used to make inferences on one psychological trait such as intelligence. Cronbach and Meehl (1955) introduced construct validity as an indirect method of validation to be used when dependent variables in knowledge, abilities and competencies field are not able to indicate the measure extent that the test aims to fulfil. 
Table 13.1 Validity aspects

\begin{tabular}{lll}
\hline & \multicolumn{2}{c}{ Validity aspects } \\
\hline \multirow{2}{*}{ Evidence } & Test interpretation & Test use \\
& Construct validity & $\begin{array}{c}\text { Construct validity } \\
+\end{array}$ \\
Consequences & Value implications & $\begin{array}{l}\text { Relevance/utility } \\
\text { Social consequences }\end{array}$ \\
\hline
\end{tabular}

Source: Messick (1989, p. 20)

Cronbach, in 1971, affirmed that validity "is not a test evaluation but an interpretation of data gathered through a specific procedure" (p. 44); in this way he realized a substantive change moving from an instrumental perspective to a more social one with a strong emphasis on the interpretation of assessment inferences, evidence sources, threatened constructs and consequences. The unitary validity framework synthesized the different forms of validity (with a new emphasis on construct validity). Messick (1989) described validity in terms of an evaluative judgment integrated with the extent to which evidence and theoretical clarifications support adequacy and appropriateness of actions realized on the base of test results (Table 13.1).

Stressing the role of social consequences related to assessment, this definition has led to a deep reconceptualization of validity as a multifaceted, unified concept. However, the inclusion of these aspects determined some practical problems. In 2006, Kane suggested an argumentative approach for validity. Interpretation, coherence and plausibility are important as well as the social dimensions. Although the literature in this research field has demonstrated a great vivacity, the practice has difficulties to follow theory in a new or emerging field of education such as informal learning. Validity is a complex and crucial issue in the field of validation and certification of informal learning. Gathered data should be functional to support inferences on performances and competencies of an individual. Validity needs quality evidence as a key step in the interpretation of informal learning results, validation and assessment. However, this criterion is hard to guarantee with informal learning due to its intrinsic nature (McGivney, 2006; Nyström, 2004; Sandberg \& Andersson, 2011; Stenlund, 2013).

With concern for validity, the validation of informal learning has to be accurate. In order to assure a valid and sound process of validation in the higher education field it is essential to

- define the purpose(s) of the validation process;

- explain in a transparent and clear way what kind of competencies (e.g. definition of learning outcomes) will be assessed;

- clearly explain the assessment criteria and the instruments that will be used;

- communicate and report to claimants, as well as to other stakeholders involved, the assessment results. 
Furthermore, it is important to use stable and predictive instruments: The reliability criterion allows to predetermine the interpretation of gathered evidence. Information is reliable when different measures of the same instrument are constant with different users and different conditions. Reliability for validation in higher education context refers "to the stability of the measurement, that is, the degree to which repeated measurements of the same object are consistent with each other" (Stenlund, 2013; p. 536). How can accuracy be guaranteed in the validation of informal learning? It is important to

- compare different assessments made by different stakeholders (e.g. using methods such as triangulation, reflection, collaboration, de-briefing) and;

- reduce the causes of inaccurate practices (e.g. unrealistic evaluation of individuals' competencies, neglected crucial information, underestimated impact of social environment and cultural background).

The risk of a validation process that loses its meaning and function can be reduced by considering how, and to what extent, validation outputs are credible.

Reconsidering validity (and reliability) leads us to reconsider validation instruments and to focus on criteria such as credibility, authenticity, meaningfulness and transformation. It is important that assessors reflect on all these criteria in order to assure transparency of procedures, impartiality and credibility of a learner's outcomes. Institutions will need to make significant changes if they want to guarantee the right to validation and the social recognition of what an individual has learned.

This brief review demonstrates how different efforts have been made to define and implement models of validation and certification of informal learning. However, the theoretical base seems still weak and repetitive. It is necessary to respond to the requirements of innovative, inclusive and accessible methodologies and approaches. Models and approaches of validation have to be reconsidered at the policy level taking into account the coherence and alignment within a national system. However, it is fundamental to reconsider the role, the functions and the competencies of actors who are responsible for the validation process. Moving from this last consideration the next section reports on how the validation and certification process has been designed and implemented in the Italian higher education system.

\section{University, competencies and informal learning}

Assessment of learning in higher education generally aims to

- mark and grade students' learning;

- foster students' learning progression;

- guide students' performance;

- facilitate students' orientation to future professional choices; 
- identify learning difficulties and scaffold students to correct errors and misconceptions;

- give feedback to teachers in order to improve their teaching practice;

- $\quad$ respond to accountability requirements.

The Italian higher education system has aligned to the international trend of recognition, validation and certification of informal learning. Following the Bologna Process perspective, these forms of assessment have been perceived as a functional response to lifelong learning and social inclusion requirements and, at the same time, as an effective driver for students' employability. However, as national and international reviews confirm, in Italy the implementation of a formalized, institutionalized, coherent system of recognition, validation and certification of informal learning in higher education still requires considerable effort. While a sufficient level of advancement has been pursued during the last 10 years in the legislative field, a screening of practices of validations (Table 13.2) reveals how these actions are more frequently framed for vocational education and workplace learning rather than for higher education.

Table 13.2 Practices of validation and certification of competencies in Italy

\begin{tabular}{|c|c|}
\hline Target & $\begin{array}{l}\text { - Unemployed workers or workers who run } \\
\text { the risk of becoming unemployed or work- } \\
\text { ers with a professional re-qualification need } \\
\text { - Workers with a need of professional } \\
\text { certification } \\
\text { - Immigrant workers with no formal } \\
\text { professional and/or educational } \\
\text { certification } \\
\text { - Young people with high-stakes qualifications } \\
\text { - Volunteers, apprentices }\end{array}$ \\
\hline Field of application & $\begin{array}{l}\text { - Training paths (since } 2008) \\
\text { - Work experience ( since 2010) } \\
\text { - Apprenticeship (since } 2013) \\
\text { - VET (since 2013) } \\
\text { - Training Internship (since } 2013 \text { ) } \\
\text { - Third sector }\end{array}$ \\
\hline Model of reference & - VAE (Validation des acquis de l'expérience) \\
\hline Instruments & $\begin{array}{l}\text { - Declarative methods } \\
\text { - Dossier and/or portfolio } \\
\text { - Technical interviews } \\
\text { - Observation/shadowing } \\
\text { - Simulations } \\
\text { - Performance assessment } \\
\text { - Written test }\end{array}$ \\
\hline $\begin{array}{l}\text { Subjects responsible } \\
\text { for Certification }\end{array}$ & $\begin{array}{l}\text { - Private agencies } \\
\text { - Associations } \\
\text { - Local authorities } \\
\text { - University }\end{array}$ \\
\hline
\end{tabular}

Source: ISFOL (2013) 
Three practices have to be considered in this framework:

- Citizen's booklet: Following the Law 50/2003 this instrument is finalized to register competencies acquired through education and training paths. Competencies acquired in non-formal paths that are documented and certified can be also registered in this document.

- Vocational training paths: Young graduate and postgraduate students, as well as unemployed people and workers, can attend these kind of courses. Validated competencies are reported and communicated in terms of credits.

- Regional qualification and certification systems: Some regions in Italy have designed instruments of qualification for the recognition of credits in relation to competencies acquired in formal and informal learning contexts.

All these actions, however, are not systemic.

The Law 92/2012 demonstrated a renewed interest in informal learning, considered for a long time as a neglected kind of learning. In the scenario designed by this new law two challenges emerged for the Italian higher education system:

1 The definition of prerequisites for recognition and validation of competencies in credentialed learning.

2 The alignment of learning outcomes in terms of competencies and professional standards. This implies a more effective dialogue between the university and other stakeholders (including the labour market and government agencies).

The Law 92/2012 addressed the main principles and criteria for the recognition and validation of informal learning:

- Recognition and validation of non-formal and informal learning aim to value the cultural and professional background of individuals and to translate it into credentialed learning (university credits).

- Recognition and validation of informal learning have to be evidence-based practices.

- Work experience is recognized as an essential component of the personal and professional lives of individuals.

- Institutions (education, training, labour market) involved in the recognition and validation processes have to guarantee a common service to individuals.

- Non-formal and informal learning have to be credentialed considering education, training standards as well professional qualifications.

- Recognition and validation have to follow criteria of simplicity, transparency, responsiveness to quality assurance system and valorization of the cultural and professional heritage of individuals.

- Equity has to be assured through national reference frameworks. 
In this scenario, the higher education system is called to review its traditional mission introducing in each university a Centre for Lifelong Learning responsible for the following actions:

- Information and orientation of students.

- Definition of admissibility procedures.

- Support in the phase of recognition of competencies (e.g. compiling a portfolio or dossier).

- Assessment and validation of credits.

- Certification of competencies.

The alignment to the European framework is clear; however, despite the legislative design the Italian universities only very slowly moved to the practical plan. While in Europe there are remarkable and consolidated experiences of recognition and validation of informal learning in higher education contexts (e.g. VAE in France, APEL in the UK, APL in Norway), in Italy a cultural gap about lifelong learning and about the power (and the role) of recognition and validation of informal learning still persists. If on the one hand, universities recognize the rationale and the value of lifelong learning, on the other hand, there is a strong resistance to transform into credits informal learning achievements considered as a suspicious learning because they have been gained through experience and not in traditional (formal) ways. As a consequence, validation and certification practices in the Italian higher education system have never been systematically implemented until recently.

\section{Conclusions}

The process of recognition, validation and certification of competence represent a key strategy to promote and support lifelong learning, assuring flexibility, transparency, transferability and employability. This value is, without doubt, announced and assured in educational and work policy perspectives. However, despite the growing use of validation and certification in higher education, as well as in work-related contexts, in Italy, the level of implementation is really scant. Also, the traditional resistance to accept a different kind of learning and the lack of attention to validity and accuracy of validation processes still impact on this kind of assessment.

This chapter has reflected on a more systemic and robust way towards the recognition, validation and certification of competencies. Dealing with only legislative aspects, as happened in Italy, demonstrates how hard it is to translate informal learning in traditional education systems like higher education.

Further research is urgently required to gain a broader understanding and a more effective practice of validation and certification of informal learning in higher education. It is necessary to "strengthen the empirical evidence-base with respect to a broad and comprehensive view of validity" (Stenlund, 2010, p. 795) and reinforce connections between empirical research, educational practice and assessment arrangements in the higher education field. This need for new 
opportunities to integrate educational research into local and/or international research pathways is strictly related to validity. In this perspective, validation and certification practice should overcome the "methodological nationalism" and allow reflection on different elements such as the following:

- What are the most relevant research questions?

- How validation and certification of competencies are studied (e.g. focus on research design and methods and not only on results)?

- How to assure the quality of the assessment practices?

- How do researchers and practitioners think about issues and problems and manage responsive and effective solutions?

Like an avant-garde movement, the recognition, validation and certification processes should be, at the same time, more rigorous (assuring validity, reliability, accuracy) and transgressive highlighting new problems (in terms of methodology) and opening new scenarios for the educational assessment in the higher education field. Only in this way will these processes release the great power that assessment has in terms of change and improvement of the existing practices, models and approaches.

\section{References}

Andersson, P., \& Guo, S. (2009). Governing through non/recognition: The missing 'R' in the PLAR for immigrant professionals in Canada and Sweden. International Journal of Lifelong Education, 28(4), 423-437.

Andersson, P., \& Harris J. (Eds.). (2006). Re-theorising the recognition of prior learning. Leicester: NIACE.

Andersson, P., Fejes, A., \& Sandberg, F. (2013). Introducing research on recognition of prior learning. International Journal of Lifelong Learning, 32(4), 405-411.

Bjørnåvold, J. (2000). Identification, assessment and recognition of non-formal learning in Europe. Making learning visible. Thessaloniki: CEDEFOP.

Bron, A., \& Schemmann, M. (Ed.). (2003). Knowledge society, information society and adult education. Bochum studies in international adult education (Vol. IV). Munster: LIT.

Castle, J., \& Attwood, G. (2001). Recognition of prior learning (RPL) for access or credit? Problematic issues in a university. Studies in the education of Adults, 33(1), 60-72.

CEDEFOP (2000). Making learning visible: Identification, assessment and recognition of non-formal learning in Europe. Thessaloniki: CEDEFOP.

CEDEFOP (2014). Use of validation by enterprise for human resource and career development purposes. Luxembourg: CEDEFOP.

CEDEFOP, European Commission (2009). European guidelines for validating non-formal and informal learning, Luxembourg: Publication Office.

Coffield, F. (2000). The necessity of informal learning. Bristol: The Policy Press.

Collardin, D., \& Bjørnåvold, J. (2005). The learning continuity: European inventory on validating non-formal and informal learning. Luxembourg: Official Publications of the European Commission, CEDEFOP.

Cooper, L., \& Harris, J. (2013). Recognition of prior learning: Exploring the 'knowledge question'. International Journal of Lifelong Education, 32(4), 447-463. 
Council of the European Commission. (2012). Council recommendation of 20 December 2012 on the validation of non-formal and informal learning. Official Journal of the European Union, C 398, 22.12.2012.

Cronbach, L. S. (1971). Test validation. In R. L. Thorndike (Ed.), Educational measurement (pp. 443-507). Washington, DC: American Council on Education.

Cronbach, L. S., \& Meehl, P. E. (1955). Construct validity. Psychological Bulletin, 52, 281-302.

DeLuca, C. (2011). Interpretive validity theory: Mapping a methodology for validating educational assessments. Educational research, 53(3), 303-320.

Evans, N. (Ed.). (2000). Experiential learning around the world. Employability and the global economy. London: Jessica Kingsley.

Fenwick, T., \& Parsons, J. (2000). The art of evaluating adult learners. Toronto: Thompson Edition.

Feutrie, M. (2008). The recognition of individual experience in a lifelong learning perspective: Validation of non-formal and informal learning in France. Lifelong learning in Europe, 13(3), 164-171.

Guilford, J. P. (1946). New standards for test evaluation. Educational and psychological measurement, 6(5), 427-439.

Harris, J. (2000). RPL: Power pedagogy and possibility. Pretoria: Human Sciences Research Council (HSRC).

ISFOL, (2013). Validazione delle competenze da esperienza: Approcci e pratiche in Italia e in Europa. Roma: Pubblicazioni ISFOL.

Jackson, S. (Ed.). (2011). Innovations in lifelong learning: Critical perspectives on diversity, participation, and vocational learning. New York, NY: Routledge.

Jarvis, P. (2011). Adult education and the changing international scene: Theoretical perspectives. PAACE Journal of Lifelong Learning, 20, 37-50.

Kane, M. T. (2006). Validation. In R. L. Brennan (Ed.)., Educational measurement (4th ed., pp. 17-64). Washington, DC: American Council on Education/Praeger.

Kane, M. T. (2016). Explicating validity. Assessment in education: Principles, policy \& practice, 23(2), 198-211.

McGivney, V. (2006). Informal learning. The challenge for research. In R., Edwards, J., Gallacher, \& S., Whittaker (Eds.), Learning outside the academy (pp. 11-23). New York, NY: Routledge.

Messick, S. (1989). Validity. In R. L., Linn (Ed.), Educational measurement (3rd ed., pp. 13-103). New York, NY: American Council on Education/Macmillan.

Michelson, E. (2006). Beyond Galileo's telescope: Situated knowledge and the recognition of prior learning. In P., Andersson, \& J., Harris (Eds.), Re-theorising the recognition of prior learning (pp. 141-162). Leicester: NIACE.

Newton, P. E. (2007). Clarifying the purposes of educational assessment. Assessment in Education, 14(2), 149-170.

Nyström, P. (2004). Reliability of educational assessments: The case of classification accuracy. Scandinavian Journal of Educational Research, 48(4), 427-440.

Pitman, T. (2009). Recognition of prior learning: The accelerated rate of change in Australian universities. Higher Education Research \& Development, 28(2), 227-240.

Pitman, T., \& Vidovich, L. (2013). Converting RPL into academic capital: Lessons from Australian universities. International Journal of Lifelong Learning, 32(4), 501-517.

Rogers, A. (2014). The base of the iceberg: Informal learning and its impact on formal and non-formal learning (Study guides in adult education). Opladen/Berlin/Toronto: Barbara Budrich Publishers. 
202 Serafina Pastore

\section{Serafina Pastore - University of Bari - 13/05/2020}

Sandberg, F., \& Andersson, P. (2011). RPL for accreditation in higher education: As a process of mutual understanding or merely life world colonisation? Assessment and Evaluation in Higher Education, 36(7), 767-780.

Shepard, L. A. (1993). Evaluating test validity. Review of Research in Education, 19, 405-450.

Singh, M. (2015). Global perspectives on recognising non-formal and informal learning: Why recognition matters. Technical and vocational education and training: Issues, concerns and prospects series (Vol. 21). Hamburg: UNESCO Institute for Lifelong learning/ Springer Open.

Slowey, M., \& Schuetze, H. G. (Eds.) (2012). Global perspectives on higher education and lifelong learners. New York, NY: Routledge.

Stenlund, T. (2013). Agreement in assessment of prior learning related to higher education: An examination of interrater and intrarater reliability. International Journal of Lifelong Learning, 32(4), 535-547.

Stenlund, T. (2010). Assessment of prior learning in higher education: A review from a validity perspective. Assessment \& Evaluation in Higher Education, 35(7), 783-797.

Trowler, P. (1996). Angels in marble?: Accrediting prior experiential learning in higher education. Studies in Higher Education, 21(1), 17-30.

Werquin, P. (2010). Recognizing non-formal and informal learning: Outcomes, policies and practices. Paris: OECD.

Werquin, P. (2014). RPL, labour markets and national qualifications framework: A policy perspective. In J., Harris, C., Whiak, \& J., Van Kleef (Eds.), Handbook of recognition of prior learning. Research into practice (pp. 86-111). Leicester, UK: NIACE. 